$\mathrm{K}$

45,7

998

\section{Limited public resources allocation model based on social fairness using an extended VIKOR method}

\author{
Wenqi Jiang \\ Nanjing University of Science and Technology, Nanjing, China
}

\begin{abstract}
Purpose - Different from manufacturing resources allocation problems, the prices and amounts of limited public service resources could not be changed with the consumers' requirements and social fairness is the most important objective for improving allocation efficiency. To measure social fairness reasonably, the purpose of this paper is fourfold: first, divide social fairness into longitudinal comparative fairness and crosswise comparative fairness, therefore providing their calculation formula and describing the comprehensive fair degree by using the interval numbers. Second, the comparison regulations of interval numbers are given and the corresponding features are also described. Third, an extension of VIKOR method is put forward for evaluating social fairness of different allocation alternatives with interval numbers. Finally, a numerical example illustrates the proposed method and clarifies the main results developed in the paper.

Design/methodology/approach - In this paper, the author depicts the social fair degree as an interval number, and thus proposes the comparison method between any two interval numbers. Based on the basis procedure of the VIKOR method, the paper proposes an extension of the fuzzy VIKOR method with the interval numbers to rank and select the compromise allocation alternatives. Finally, a numerical example illustrates the practicability of the proposed method.

Findings - The comparison of interval numbers is very important when the author evaluates the decision alternatives. Through analyzing the present comparison methods, the paper proposes the simple method of comparing the interval numbers, which can obtain the same results with the above two methods. The fuzzy VIKOR method, a popular multi-criteria decision-making method, focusses on ranking and selecting from a set of alternatives in a fuzzy environment. For the fuzzy value, the paper also proposes the extension of the VIKOR method to perform an evaluation and get the compromise alternatives.

Originality/value - According to the huge customers' requirement, how to improve their social fair degree has become the focus in public service resources allocation, where the social fair degree may be a comprehensive concept which includes the fair degree compared with all the other allocation alternatives and the fair degree compared with the other small group under the same allocation alternative. In the paper, the author defines the above two types of fair degree and then depicts the comprehensive fair degree as their integration, which will be interval numbers.
\end{abstract}

Keywords Decision making, Mathematical modelling

Paper type Research paper

(C) Wenqi Jiang. Published by Emerald Group Publishing Limited. This article is published under the Creative Commons Attribution (CC BY 3.0) licence. Anyone may reproduce, distribute, translate and create derivative works of this article (for both commercial and non-commercial purposes) subject to full attribution to the original publication and authors. The full terms of this licence may be seen at http://creativecommons.org/licences/by/3.0/legalcode

This research was supported by National Natural Science Foundation of China (No. 71271116) and the independent scientific research project of Nanjing University of Science and Technology (No. 30916011331). 


\section{Introduction}

Resource allocation is a process by which limited resources such as the human resources in the public education network (López-Torres and Prior, 2016), the emergency medical resources (Sung and Lee, 2016), the research and development project resources (Xiong et al., 2016), the water resources (Hu et al., 2016), the energyefficient resources (Xu et al., 2016) and so forth are allocated to various channels reasonably so as to achieve a certain objective.

Regarding different optimization objectives in the diverse scenarios, the resources allocation (RA) problems are divided into single objective RA problems which only optimize an objective, and multiple objective RA problems which will optimize several objectives simultaneously. For the former, the objective is often minimal cost or maximal profit, whereas several objectives will be integrated in the latter, and the corresponding algorithms are proposed. In recent literature, the latter is considered as a multi-criteria decision-making (MCDM) problem; some MCDM methods could consequently be utilized to evaluate the performance of RA problems such as data envelop analysis (DEA). Hakim et al. (2016) presented a bi-level DEA model for centralized RA problems considering the lower bounds on the efficiencies of decisionmaking units. Yang and Zhang (2015) designed characteristic functions based on DEA efficiency to solve RA problems in a fair way. Fang and Li (2015) presented a centralized DEA approach for reallocating resources based on revenue efficiency across a set of decision-making units under a centralized environment. Equally, a multiple-dimensional fairness approach based on the priorities was presented with several criteria (Pla et al., 2015). The decision makers' preferences were incorporated into RA problems by DEA (Wu et al., 2013; Fang, 2013).

Some scholars have provided some algorithms to search the optimal allocation alternatives. Sung and Lee (2016) proposed a column generation algorithm to efficiently handle a large number of feasible ambulance schedules. A cooperative co-evolutionary multi-objective algorithm was designed to produce high-quality solutions (Xiong et al., 2016). Zhang et al. (2016) divided RA problems into two stages in which the first stage was to minimize the total losses, while the second optimized RA problems by using the proposed heuristic algorithm in the polynomial complexity. Equally, a compromise programming method was employed to trade off the economic benefit efficiency and equity in the water allocation problems (Hu et al., 2016). Kaushik and Vidyarthi (2016) implemented the energy saving mechanism by using a dynamic threshold method, followed by the genetic algorithm (GA). Shabtay et al. (2016) developed a pseudo-polynomial algorithm and a fully polynomial time approximation scheme to minimize the total weighted number of tardy jobs plus due date assignment costs subject to an upper bound on the total weighted resource consumption. The hybrid quantum particle swarm optimization was used to solve the chanceconstrained RA problems (Xu et al., 2016). Kataoka and Yamada (2016) reformulated d-MSTRA as the knapsack and solved RA problems using a previously published branch and bound algorithm. Alikhani and Azar (2015) proposed an integrated satisfying optimization method based on fuzzy goal programming and logarithmic fuzzy preference programming for sustainable gas RA problem. Likewise, the use of a differential evolution combined with a multi-objective optimization algorithm was proposed to allocate the resources to the users in a downlink OFDMA system (Sharma and Anpalagan, 2015). Pandremmenou et al. (2015) studied two optimization criteria for the optimal allocation of the source and channel coding rates, which are continuous, under transmission bit rate constraints. A binary optimization framework was given 
$\mathrm{K}$

45,7

1000

for modeling the dynamic RA problems (Bertsimas et al., 2014). The biological based GAs was also proposed for optimized disaster response RA problems (Chou et al., 2014), and the approach combining the voting method and the lexicographic goal programming model involved both qualitative and quantitative factors in the RA problems (Yu and $\mathrm{Hu}, 2014)$. An effective modified binary particle swarm optimization algorithm was also proposed for multi-objective RA problems (Fan et al., 2013).

The recent research literature of RA problems focus on the competitive manufacturing RA, in which the amounts and prices of these resources could be adjusted according to the consumers' requirements. Along with the development of the modern service industry, the service RA (SRA) problems have become much more important in practice, especially the public SRA problems. Different from the above manufacturing resources, the price of some public services resources could not be changed with the needs of the customers, in which the social fairness of public SRA is the most critical objective of measuring their efficiency. How to improve the social fairness of the limited public SRA problems has become a hot research topic. To solve the above difficulties, it is necessary to analyze the features of the public SRA problems, and identify the differences between the manufacturing resources and the service resources, and therefore propose a feasible approach to allocate the public service resources.

The remainder of this paper is organized as follows: in Section 2, the public SRA problems are described in detail and the comprehensive fair degree is also defined. Section 4 compares the interval numbers. In Section 5, the paper proposes the VIKOR method to obtain the compromise solutions of the SRA problems. In Section 6, a numerical example of the train tickets allocation is applied to illustrate the proposed procedure. The conclusions are presented in Section 7.

\section{The feature of the public SRA problem}

In China, the imbalance in different provinces and different districts within the provinces leads to huge-scale population movements. Millions of migrant workers leave their hometowns in search of work opportunities and must return to their hometowns in order to celebrate the spring festival every year, similar to the Christmas festival in some countries. Spring carry is seen as the most large-scale collective migration in the world, with a unique festival landscape.

During the spring festival, persons may ride motor-bikes or coaches, drive their cars, fly and so on; among these, trains are the preferred means of transport because of the lower price and higher safety. The official statistics show that there were more than 2.9 billion passenger trips in 2016 spring transportation; only 11 percent of passengers succeeded in purchasing train tickets. Passenger rail purchasing of a ticket is hard especially for scalping tickets, then they often complain about those difficulties.

The Chinese Government and China Railway Corporation (CRC) have made continued efforts to improve the above transportation difficulties, and they built the high-speed railway to ease pressure on congested road and air transport systems; conversely, the railway transport cannot be improved in the short term. In order to improve the service quality and decrease the complaints made, $\mathrm{CRC}$ have taken various measures such as enabling the booking of train tickets by network platforms and searching if the train is late. Taking advantage of the internet, some passengers can get the information they want, which helps save time and makes travel more convenient. Even though the CRC have made considerable efforts, some passengers, however, are not content with the results. 
Recently, the CRC provided four types of booking tickets, which are online booking, Limited public ticket window, ticket booking and telephone booking outlets, respectively. Meanwhile, CRC set different lead times for these four types of tickets. The advantages and disadvantages of the above channels can be seen in Table I.

It is obvious that different passengers have different preferences for the four channels. To book the train tickets successfully, they need to evaluate comprehensively the lead time and the advantages and disadvantages of the above four types, and thus make a final decision.

Similar to the train ticket allocation problems, well-known experts in famous hospitals are very limited and are far short of medical requirements. For instance, well-known experts in several hospitals in Shanghai represented only 1.69 percent in 2015 , and it is very hard to register for the medical outpatient service for these patients. To reduce the invalid waiting times in the treatment process, some Chinese hospitals have carried out multiple measures such as online register, window register and telephone register. The performances have not been improved significantly in these hospitals over the years. Social fairness may be lost if all specialists are allocated freely with multiple measures with limited resources, i.e. the patients who wait in line may not often book successfully.

In conclusion, the above two types of difficulties have some common features, which could be depicted as follows:

(1) all the above service resources are public resources which cannot be extended in the short term;

(2) the consumers of the service resources have different preferences for different channels, and the mumbers of consumers are very huge; and

(3) social fairness is the most important objective, and the price of the service resources cannot be changed with the consumers.

\section{The measurement of the social fairness in public SRA}

Fairness theory is also called the social comparative theory, where the comparison is divided into a longitudinal comparison and a crosswise comparison. The former compares his/her rewards with the last rewards, whereas the latter compares his/her rewards with the others.

Fairness is a perceptual cognition in contemporary social and organizational psychology, which could traditionally be divided into three types: distributive, procedural and interactional. In order to describe the complicated construct, how to measure fairness becomes a critical question.

\begin{tabular}{lll}
\hline & Advantage & Disadvantage \\
\hline Online booking & $\begin{array}{l}\text { Convenient } \\
\text { No need to wait in line }\end{array}$ & $\begin{array}{l}\text { Difficult to select appropriate seats sometimes, and need to } \\
\text { go to the railway station to obtain train tickets }\end{array}$ \\
Ticket window & Select seats freely & Sometimes, wait for a long time \\
Ticket booking & $\begin{array}{l}\text { Near distances and can } \\
\text { select seats freely }\end{array}$ & Pay more money for tickets \\
Telephone & $\begin{array}{l}\text { Not always successful in } \\
\text { booking outlets }\end{array}$ & Pooking tickets
\end{tabular}

Table I.

The comparison of the four types of tickets 
K

45,7

The measurement of fairness perception is not simple as it is a subjective, complex, vague and ambiguous construct (Azar and Darvishi, 2011). Persons usually determine whether they have been treated fairly first by examining the ratio of their inputs relevant to their outcomes and then by comparing this ratio to the inputs-to-outcomes ratio of a referent other (Park et al., 2010); furthermore, their own thoughts, past experiences and personal modes of thinking will also affect the final perception of fairness. It may be impossible to acquire the individual fairness by performing social investigations for a large number of consumers.

To simplify the above difficulties, we can divide the consumers into several consumer groups in relation to the market channels, and make a feasible decision by their features.

Assume that there are $\mathrm{n}$ consumer group $S M_{j}$ and $\mathrm{m}$ allocation alternatives $A_{i}$ for each $S M_{j}$ (the total resources are R), let $a_{i j}$ be the allocated amounts of $S M_{j}$ according to $A_{i}$. Thus, the allocation matrix is $A=\left[a_{i j}\right]_{m \times n}, i \in(1, \ldots, m), j \in(1, \ldots, n)$ where $\sum_{j=1}^{n} a_{i j}=R$ for any alternatives $A_{i}$.

For any $S M_{j}$, the more resources they obtain, the higher their fairness perception. We thus describe the longitudinal comparison and crosswise comparison as Definitions 1 and 2, respectively:

Definition 1. Suppose that the amounts of $S M_{j}$ allocated are $c_{j}$ and $k_{i j}\left(k_{i j}=a_{i j} / c_{j}\right)$ is their per capita occupancy; then the correspondent RA matrix can be $K=\left[k_{i j}\right]_{m \times n}$. Let $k_{j}^{+}=\max _{i} k_{i j}$ and $k_{j}^{-}=\min _{i} k_{i j}$ and the longitudinal comparisive degree is:

$$
s_{i j}^{l}=\frac{k_{i j}-k_{j}^{-}}{k_{j}^{+}-k_{j}^{-}}, \quad i=1,2, \cdots, m, j \in(1, \cdots, n)
$$

where $s_{i j}^{l} \in[0,1]$; the greater $s_{i j}^{l}$ is, the higher the longitudinal comparisive degree of $S M_{j}$ is.

Definition 2. Let $s_{i j l}^{c}$ be the crosswise comparisive degree of $S M_{j}$ compared with $S M_{l}$ under the same allocation alternatives; then the integrated crosswise comparisive degree $s_{i j}^{c}$ of $S M_{j}$ could be as follows:

$$
\begin{aligned}
s_{i j}^{c} & =\frac{1}{n-1} \sum_{l, l \neq j} s_{i j l}^{r}, \quad s_{i j l}^{c}=\frac{k_{i j}}{k_{i j}+k_{i l}}, j \neq l ; \quad j, l=1,2, \cdots, n, \\
i & =1, \cdots, m
\end{aligned}
$$

Based on Definitions 1 and 2, the comprehensive fair degree $s_{i j}$ of $S M_{j}$ could be calculated by the following equation if the linear model is applied:

$$
s_{i j}=\alpha_{i j} s_{i j}^{l}+\left(1-\alpha_{i j}\right) s_{i j}^{c}, 0 \leqslant \alpha_{i j} \leqslant 1
$$

If $\alpha_{i j}$ is closer to 0 , then $s_{i j}$ is nearer to $s_{i j}^{c}$; otherwise $s_{i j}$ is nearer to $s_{i j}^{l} . \alpha_{i j}$ may affect the final comprehensive fair degree; thus, it is reasonable to depict $s_{i j}$ as an interval number and not a crisp number, where $s_{i j}=\left[\min \left(s_{i j}^{l}, s_{i j}^{c}\right), \max \left(s_{i j}^{l}, s_{i j}^{c}\right)\right]$. 
For different public RA alternatives, the resource owners need to evaluate Limited public comprehensively and select the optimal allocation alternatives by the maximal fair degree. Here the RA problems could be regarded as an MCDM problem.

\section{The comparison of different interval numbers}

In the fuzzy MCDM problems with interval numbers, Moore (1979) used two transitive order relations defined over the interval numbers, which could not explain the ranking between two overlapping interval numbers. Ishibuchi and Tanaka (1990) ranked the interval numbers more prominently and did not compare pairs of the interval numbers. Sengupta and Pal (2000) constructed a premise which implied that an interval number is inferior to the other interval numbers in terms of the values. To compare the interval numbers effectively, we describe the following regulations:

Definition 3. Suppose $\tilde{A}=\left[a^{L}, a^{R}\right]$ and $\tilde{B}=\left[b^{L}, b^{R}\right]$ are any two interval numbers; then the arithmetic operations are displayed as follows:

Addition:

$$
\tilde{A}+\tilde{B}=\left[a^{L}+b^{L}, a^{R}+b^{R}\right]
$$

Subtraction:

$$
\tilde{A}-\tilde{B}=\left[a^{L}-b^{R}, a^{R}-b^{L}\right]
$$

Multiplication:

$$
\tilde{A} \times \tilde{B}=\left[a^{L} \times b^{L}, a^{R} \times b^{R}\right]
$$

Division:

$$
\tilde{A} / \tilde{B}=\left[a^{L} / b^{R}, a^{R} / b^{L}\right]
$$

Definition 4. Let $m(\tilde{A})=0.5\left(a^{L}+a^{R}\right), m(\tilde{B})=0.5\left(b^{L}+b^{R}\right), w(\tilde{A})=0.5\left(a^{R}-a^{L}\right)$ and $w(\tilde{B})=0.5\left(b^{R}-b^{L}\right)$; the acceptability degree $\wp(\tilde{A}<\tilde{B})$ or $\wp_{<}(\tilde{A}, \tilde{B})$ may be interpreted further on the basis of the comparative position of the mean and width of the interval numbers:

$$
\wp(\tilde{A}<\tilde{B})=\frac{m(\tilde{B})-m(\tilde{A})}{w(\tilde{B})+w(\tilde{A})}
$$

It is difficult to distinguish which is more than the other interval numbers. If $m(\tilde{B})=m(\tilde{A})$, it is hard to judge if $\tilde{A}$ is preferred to $\tilde{B}$ with Equation (4). Xu (2008) defined the degree of possibility $P(\tilde{A} \geqslant \tilde{B})$ for $\tilde{A} \geqslant \tilde{B}$, which is shown in the following equation:

$$
P(\tilde{A} \geqslant \tilde{B})=\max \left\{1-\max \left(\frac{b^{R}-a^{L}}{a^{R}-a^{L}+b^{R}-b^{L}}, 0\right), 0\right\}
$$


$\mathrm{K}$

45,7
Proposition 1. $P(\tilde{A} \geqslant \tilde{B}) \geqslant 0.5$ when $m(\tilde{A}) \geqslant m(\tilde{B})$, and $P(\tilde{A} \geqslant \tilde{B})$ satisfies the transitive relation.

Proof. If $m(\tilde{A}) \geqslant m(\tilde{B})$, then $a^{R}+a \geqslant b^{R}+b^{L}$; we can obtain $a^{R}-b^{L} \geqslant b^{R}-a^{L}$.

If $b^{R} \leqslant a^{L}$, then $a^{R}+a^{L}>b^{R}+b^{L}$ and $a^{R}-a^{L}+b^{R}-b^{L}>0$.

Because:

\section{4}

then $P(\tilde{A} \geqslant \tilde{B})=1$.

When $b^{R}>a^{L}$ :

$$
\frac{b^{R}-a^{L}}{a^{R}-a^{L}+b^{R}-b^{L}} \leqslant \frac{b^{R}-a^{L}}{2\left(b^{R}-a^{L}\right)}=0.5,
$$

then $P(\tilde{A} \geqslant \tilde{B}) \geqslant 0.5$

Let $\tilde{C}=\left[c^{L}, c^{R}\right]$; then $P(\tilde{A} \geqslant \tilde{B}) \geqslant 0.5$ and $P(\tilde{B} \geqslant \tilde{C}) \geqslant 0.5$ if $\tilde{A} \geqslant \tilde{B}$ and $\tilde{B} \geqslant \tilde{C}$.

Because $a^{R}+a^{L}>b^{R}+b^{L}>c^{R}+c^{L}$ :

$$
\max \left(\frac{c^{R}-a^{L}}{a^{R}-a^{L}+c^{R}-c^{L}}, 0\right)<0.5
$$

then:

$$
P(\tilde{A} \geqslant \tilde{C})>0.5
$$

Jiang et al. (2008) divided the relations between two interval numbers into six types and the possibility degrees between them can be seen in the following equation:

$$
P_{\tilde{A} \geqslant \tilde{B}}= \begin{cases}1 & a^{L} \geqslant b^{R} \\ \frac{a^{R}-b^{R}}{a^{R}-a^{L}}+\frac{b^{R}-a^{L}}{a^{R}-a^{L}} \times \frac{a^{L}-b^{L}}{b^{R}-b^{L}}+0.5 \times \frac{b^{R}-a^{L}}{a^{R}-a^{L}} \times \frac{b^{R}-a^{L}}{b^{R}-b^{L}} & b^{L} \leqslant a^{L} \leqslant b^{R} \leqslant a^{R} \\ \frac{a^{R}-b^{R}}{a^{R}}+0.5 \times \frac{b^{R}-b^{L}}{a^{R}-a^{L}} & a^{L}<b^{L}<b^{R} \leqslant a^{R} \\ 0.5 \times \frac{a^{R}-b^{L}}{a^{R}-a^{L}} \times \frac{a^{R}-b^{L}}{b^{R}-b^{L}} & a^{L}<b^{L}<a^{R} \leqslant b^{R} \\ \frac{a^{L}-b^{L}}{b^{R}-b^{L}}+0.5 \times \frac{a^{R}-a^{L}}{b^{R}-b^{L}} & b^{L} \leqslant a^{L}<a^{R} \leqslant b^{R} \\ 0 & a^{R}<b^{L}\end{cases}
$$

This kind of the possibility degree also satisfies the feature defined in $P 1$ :

Proof. For $P(\tilde{A} \geqslant \tilde{B})+P(\tilde{B} \geqslant \tilde{A})=1$, we can analyze the three types among the six types accordingly in Equation (6).

If $a^{L} \geqslant b^{R}$, then $a^{R}+a^{L} \geqslant b^{R}+b^{L}$ and $P_{\tilde{A}} \geqslant \tilde{B}=1>0.5$. 
If $a^{L}<b^{L}<b^{R} \leqslant a^{R}$, suppose $P_{\tilde{A} \geqslant \tilde{B}}>0.5$; then:

$$
\frac{a^{R}-b^{R}}{a^{R}-a^{L}}+0.5 \times \frac{b^{R}-b^{L}}{a^{R}-a^{L}}>0.5
$$

we can obtain $a^{R}+a^{L} \geqslant b^{R}+b^{L}$.

If $a^{L}<b^{L}<a^{R} \leqslant b^{R}$, then $a^{R}+a^{L}<b^{R}+b^{L}$.

Because:

then:

$$
0<\frac{a^{R}-b^{L}}{a^{R}-a^{L}}<1 \text { and } 0<\frac{a^{R}-b^{L}}{b^{R}-b^{L}}<1
$$

$$
P_{\tilde{A} \geqslant \tilde{B}}=0.5 \times \frac{a^{R}-b^{L}}{a^{R}-a^{L}} \times \frac{a^{R}-b^{L}}{b^{R}-b^{L}}<0.5
$$

then:

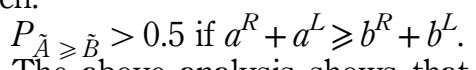

The above analysis shows that we only need to calculate $m(\tilde{A})$ and $m(\tilde{B})$ and compare them directly if we select the maximal and minimal interval numbers among many interval numbers.

If $m(\tilde{A})=m(\tilde{B})$, we calculate the possibility degrees with Equation (6); then select the maximal interval numbers between $\tilde{A}$ and $\tilde{B}$.

If $m(\tilde{A})=m(\tilde{B})$ and $P_{\tilde{A}} \geqslant \tilde{B}=0.5, \tilde{A}$ and $\tilde{B}$ can be considered as the same interval numbers.

\section{The proposed method}

As an MCDM method, the VIKOR method was developed for multi-criteria optimization in complex systems (Opricovic and Tzeng, 2004) and had been successfully used for material selection (Yazdani and Payam, 2015), failure mode and effect analysis (Liu et al., 2015), green supply chain management (Rostamzadeh et al., 2015; Akman, 2015), municipal solid waste management (Aghajani Mir et al., 2016), reverse logistics (Vahabzadeh et al., 2015) and supplier selection (You et al., 2015). Equally, they have been tackle the MCDM problems with the interval valued fuzzy numbers (Kuo and Liang, 2012; Sayadi et al., 2009).

In the VIKOR method, the compromise solution is a feasible solution which is the closest to the ideal solution, where compromise means an agreement established by mutual concessions (Opricovic and Tzeng, 2007). The multi-criteria measure for compromise ranking is developed from the $L_{p}$-metric used as an aggregating function.

Let $1 \leqslant p \leqslant \infty, i \in(1, \ldots, m)$; then:

$$
L_{p i}=\left\{\sum_{j=1}^{n}\left[w_{j}\left(\max _{1 \leqslant i \leqslant m}\left(s_{i j}\right)-s_{i j}\right) /\left(\max _{1 \leqslant i \leqslant m}\left(s_{i j}\right)-\min _{1 \leqslant i \leqslant m}\left(s_{i j}\right)\right)\right]^{p}\right\}^{1 / p}
$$

$L_{1 i}\left(\right.$ as $\left.S_{i}\right)$ and $L_{\infty i}\left(\right.$ as $\left.R_{i}\right)$ are employed here to attain measures and rankings, where $S_{i}$ is the group utility of the alternative $A_{i}$ and $R_{i}$ is the individual regret of the opponent.

To improve the comprehensive fair degree of the consumers, we intend to apply the VIKOR method to perform a comprehensive evaluation.

Step 1: calculate $s_{i j}$, which is $\left[\min \left(s_{i j}^{l}, s_{i j}^{c}\right), \max \left(s_{i j}^{l}, s_{i j}^{c}\right)\right]$ (see Equation (3)). 
$\mathrm{K}$

45,7

Step 2: determine the positive $s_{j}^{+}$and negative ideal points $s_{j}^{-}$for each $S M_{j}$, respectively. Each $C_{j}$ is the benefit criterion here; then:

$$
A^{+}=\left\{s_{1}^{+}, \cdots, s_{n}^{+}\right\}=\left\{\max _{i} s_{i j} \mid j=1,2, \cdots, n\right\}
$$

$$
A^{-}=\left\{s_{1}^{-}, \cdots, s_{n}^{-}\right\}=\left\{\min _{i} s_{i j} \mid j=1,2, \cdots, n\right\}
$$

We can calculate and rank $m\left(s_{i j}\right)$ for each $C_{j}$, then select the maximal and minimal interval numbers straight forwardly for the positive and negative points, and do not compare two interval numbers with the above six statuses (see Equation (6)). Let $w=\left(w_{1}, w_{2}, \ldots, w_{n}\right)$ be the weight set of $S M_{j}$ given by the resource suppliers and $\sum_{j=1}^{n} w_{j}=1$.

Step 3: calculate $S_{i}$ and $R_{i}$ :

$$
\begin{gathered}
S_{i}=\sum_{j=1}^{n} w_{j}\left(\frac{s_{j}^{+}-s_{i j}}{s_{j}^{+}-s_{j}^{-}}\right), \quad i=1,2, \cdots, m \\
R_{i}=\max \left\{w_{j}\left(\frac{s_{j}^{+}-s_{i j}}{s_{j}^{+}-s_{j}^{-}}\right) \mid j \in(1,2, \cdots, n)\right\}, \quad i=1,2, \cdots, m
\end{gathered}
$$

Step 4: calculate $Q_{i}$ :

$$
Q_{i}=v \frac{\left(S_{i}-S^{+}\right)}{\left(S^{-}-S^{+}\right)}+(1-v) \frac{\left(R_{i}-R^{+}\right)}{\left(R^{-}-R^{+}\right)}
$$

where $S^{+}=\min S_{i}, S^{-}=\max S_{i}, R^{+}=\min R_{i}$ and $R^{-}=\max _{i} R_{i} . v$ is introduced as the weight of the strategy of "the majority of criteria" (or "the maximum group utility").

Step 5: obtain the compromise solutions based on the following conditions.

Name the alternative with minimum $Q_{i}$ as $A^{\prime}$ and $A^{\prime}$ will be unique, the best alternative, if the following two conditions are satisfied:

Condition 1: acceptable advantage (improvement exceeds a certain level):

$$
Q\left(A^{\prime \prime}\right)-Q\left(A^{\prime}\right) \geqslant 1 /(m-1)
$$

Suppose $A^{\prime}=\left[a^{L}, a^{R}\right]$ and $A^{\prime \prime}=\left[b^{L}, b^{R}\right]$; then $Q\left(A^{\prime \prime}\right)-Q\left(A^{\prime}\right)$ can be calculated as follows by using the Euclidean distance:

$$
Q\left(A^{\prime \prime}\right)-Q\left(A^{\prime}\right)=\sqrt{\left(a^{L}-b^{L}\right)^{2}+\left(a^{R}-b^{R}\right)^{2}}
$$

where $A^{\prime \prime}$ is the alternative ranked second by $Q_{i}$ and $m$ is the number of alternatives.

Condition 2: acceptable stability.

Alternative $A^{\prime}$ must also be placed at the top when ranked by $S_{i}$ or $R_{i}$. 
If either condition described above is not satisfied, then a set of compromise Limited public solutions exists:

(1) if only condition 1 is satisfied, then $A^{\prime}$ and $A^{\prime \prime}$ are compromise solutions; and

(2) if condition 1 is not satisfied, then $A^{\prime}, A^{\prime \prime}, \cdots, A^{(M)}$ are all compromise solutions. Note that the index M can be determined through $Q\left(A^{(M)}\right)-Q\left(A^{\prime}\right)<1 /(m-1)$ for the maximum $M$.

\section{Numerical example}

Shanghai is the Chinese center of economic, finance and trade, which has a lot of companies and job prospects. Anqing is a developing city which includes one city and seven counties, and has a population of more than six million; more than 90 percent of the population includes farmers who need to leave Anqing city to search for jobs. There is only one train K8434 from Shanghai city to Anqing city. The general amount of K8434 tickets sold each day is 2,400.

CRC set different pre-sale periods for the booking channels in 2016 spring transportation, which is 60 days for online booking and telephone booking outlets and 58 days for ticket window and ticket booking. In total, the 12,306 booking website traffic was so heavy that the website crashed regularly because many passengers selected online booking; passengers who book tickets from ticket windows may be wasting their time waiting in line as the train tickets would have been sold out from online booking. Most passengers are unsatisfied with the above regulations. CRC intends to change the mode of train ticket allocation based on social fairness to allocate train tickets reasonably.

We investigated the specific numbers sold over eight days and the channels sold from the Shanghai Railway Administration. The investigation indicated that there are three main types which are online booking, ticket booking and ticket window, the corresponding groups matching the three types are $S M_{1}, S M_{2}$ and $S M_{3}$, respectively. The number of the group who intended to book K8434 train tickets through clicking the 12,306 website is 1,998 . We counted the number of passengers in the ticket room and the railway stations: 999 and 1,896 for ticket booking and ticket windows, respectively.

The numbers sold successfully are shown in Table II.

Based on the proposed methods in Section 5, we could perform a comprehensive evaluation for the train ticket allocation alternatives with social fairness.

Step 1: based on the method in Section 2, $s_{i j}^{l}$ and $s_{i j}^{r}$ can be calculated in Table III.

Then $s_{i j}$ can be calculated by using Equation (3) in Table IV.

Step 2: determine the positive and negative ideal points $s_{j}^{+}$and $s_{j}^{-}$(Table V).

\begin{tabular}{|c|c|c|c|c|c|}
\hline Date & Alternative & $S M_{1}$ & $S M_{2}$ & $S M_{3}$ & \\
\hline January 20, 2016 & $A_{1}$ & 1,700 & 100 & 600 & \\
\hline January 21, 2016 & $A_{2}$ & 1,000 & 200 & 1,200 & \\
\hline January 22, 2016 & $A_{3}$ & 500 & 300 & 1,600 & \\
\hline January 23, 2016 & $A_{4}$ & 1,200 & 400 & 800 & \\
\hline January 24, 2016 & $A_{5}$ & 1,050 & 400 & 950 & \\
\hline January 25, 2016 & $A_{6}$ & 1,500 & 500 & 400 & Table II. \\
\hline January 26, 2016 & $A_{7}$ & 700 & 600 & 1,100 & The numbers of \\
\hline January 27, 2016 & $A_{8}$ & 800 & 800 & 800 & train tickets sold \\
\hline
\end{tabular}


$\mathrm{K}$

45,7

\begin{tabular}{|c|c|c|c|c|c|c|c|}
\hline \multirow{2}{*}{$\begin{array}{l}\mathrm{K} \\
45,7\end{array}$} & & \multirow{2}{*}{\multicolumn{3}{|c|}{$s_{i j}^{l}$}} & \multirow{2}{*}{\multicolumn{3}{|c|}{$s_{i j}^{c}$}} \\
\hline & & & & & & & \\
\hline \multirow[b]{4}{*}{1008} & $A_{1}$ & 1.000 & 0.000 & 0.167 & 0.812 & 0.173 & 0.515 \\
\hline & $A_{2}$ & 0.417 & 0.143 & 0.667 & 0.578 & 0.263 & 0.659 \\
\hline & $A_{3}$ & 0.000 & 0.286 & 1.000 & 0.342 & 0.404 & 0.754 \\
\hline & $A_{4}$ & 0.583 & 0.429 & 0.333 & 0.594 & 0.444 & 0.463 \\
\hline \multirow{4}{*}{$\begin{array}{l}\text { Table III. } \\
\text { The fair degrees } \\
s_{i j}^{l} \text { and } s_{i j}^{r}\end{array}$} & $A_{5}$ & 0.458 & 0.429 & 0.458 & 0.540 & 0.438 & 0.522 \\
\hline & $A_{6}$ & 0.833 & 0.571 & 0.000 & 0.690 & 0.552 & 0.258 \\
\hline & $A_{7}$ & 0.167 & 0.714 & 0.583 & 0.373 & 0.570 & 0.557 \\
\hline & $A_{8}$ & 0.250 & 1.000 & 0.333 & 0.410 & 0.661 & 0.429 \\
\hline
\end{tabular}

\begin{tabular}{cccc}
\hline & $S M_{1}$ & $S M_{2}$ & $S M_{3}$ \\
\hline$A_{1}$ & {$[0.8119,1.0000]$} & {$[0.0000,0.1729]$} & {$[0.1667,0.5152]$} \\
$A_{2}$ & {$[0.4167,0.5781]$} & {$[0.1429,0.2631]$} & {$[0.6588,0.6667]$} \\
$A_{3}$ & {$[0.0000,0.3417]$} & {$[0.2857,0.4041]$} & {$[0.7542,1.0000]$} \\
$A_{4}$ & {$[0.5833,0.5938]$} & {$[0.4286,0.4436]$} & {$[0.3333,0.4626]$} \\
$A_{5}$ & {$[0.4583,0.5399]$} & {$[0.4286,0.4384]$} & {$[0.4583,0.5217]$} \\
$A_{6}$ & {$[0.6904,0.8333]$} & {$[0.5519,0.5714]$} & {$[0.0000,0.2577]$} \\
$A_{7}$ & {$[0.1667,0.3726]$} & {$[0.5703,0.7143]$} & {$[0.5572,0.5833]$} \\
$A_{8}$ & {$[0.2500,0.4103]$} & {$[0.6609,1.0000]$} & {$[0.3333,0.4288]$}
\end{tabular}

Table V.

The positive and negative ideal points

\begin{tabular}{cccc}
\hline & $S M_{1}$ & $S M_{2}$ & $S M_{3}$ \\
\hline$s_{j}^{+}$ & {$[0.8119,1.0000]$} & {$[0.6609,1.0000]$} & {$[0.7542,1.0000]$} \\
$s_{j}^{-}$ & {$[0.0000,0.3417]$} & {$[0.0000,0.1729]$} & {$[0.0000,0.2577]$}
\end{tabular}

Step 3: suppose the weights of the three groups are 0.3, 0.3 and 0.4, respectively. Then, we will compute $S_{i}$ and $R_{i}$ (see Table VI).

In Table VI, $S^{-}=[0.1856,1.4061], S^{+}=[0.1841,1.1527], R^{-}=[0.1986,0.8057]$ and $R^{+}=[0.0930,0.4364]$.

Step 4: calculate $Q_{i}$. Suppose $v=0.5$; then $Q_{i}$ can be depicted as Table VI.

Step 5: the compromise solution is $A_{5}$.

\begin{tabular}{lcccc}
\cline { 3 - 4 } & & {$\left[S_{i}^{L}, S_{i}^{U}\right]$} & {$\left[R_{i}^{L}, R_{i}^{U}\right]$} & {$\left[Q_{i}^{L}, Q_{i}^{U}\right]$} \\
\cline { 2 - 4 } & $A_{1}$ & {$[0.1886,1.4061]$} & {$[0.0956,0.6714]$} & {$[-4.5115,6.0118]$} \\
& $A_{2}$ & {$[0.2245,1.1740]$} & {$[0.1193,0.5269]$} & {$[-4.3088,4.7968]$} \\
& $A_{3}$ & {$[0.1198,1.2751]$} & {$[0.1411,0.6380]$} & {$[-4.6739,5.4277]$} \\
& $A_{4}$ & {$[0.2473,1.1542]$} & {$[0.1166,0.5371]$} & {$[-4.2252,4.7409]$} \\
& $A_{5}$ & {$[0.2414,1.1333]$} & {$[0.0930,0.4364]$} & {$[-4.2981,4.4462]$} \\
Table VI. & $A_{6}$ & {$[0.2190,1.2787]$} & {$[0.1986,0.8057]$} & {$[-4.1635,5.7948]$} \\
$S, R$ and $Q$ & $A_{7}$ & {$[0.1841,1.1527]$} & {$[0.1318,0.5317]$} & {$[-4.4410,4.7233]$} \\
& $A_{8}$ & {$[0.1489,1.2241]$} & {$[0.1302,0.5371]$} & {$[-4.5826,5.0149]$} \\
\hline
\end{tabular}

Table VI.

$S, R$ and $Q$
Table IV.

The comprehensive fair degree matrix
$[0.0000,0.1729]$

[0.2857, 0.4041]

[0.4286, 0.4436$]$

$[0.6609,1.0000]$
[0.1667, 0.5152]

$[0.7542,1.0000]$

$[0.3333,0.4626]$

[0.4583, 0.5217]

$[0.5572,0.5833]$

[0.3333, 0.4288] 
In Step 2, if we apply Equation (5) to determine the positive and negative ideal points $s_{j}^{+}$ and $s_{j}^{-}$, we should analyze the left and right endpoints for different interval numbers and then calculate the possibility degrees, which can be seen in Table VI.

The possibility degrees of interval numbers by Equation (6) can be seen in Table VIII.

Based on the comparison of the interval numbers in Tables VII and VIII, we can obtain the same results with Table V; however, it is more complicated than the method proposed in the paper.

\section{Conclusion}

Public SRA is an important topic in practices. Social fairness is a critical goal for evaluating the performances allocated. Nevertheless, fair degree is often intuitive and cognitive; it is very difficult to measure this. The main contribution of the study is to decompose the fair degree into a longitudinal comparisive degree and a crosswise comparisive degree, thus synthesizing the two degrees into a comprehensive fair

\begin{tabular}{|c|c|c|c|c|c|c|c|c|}
\hline & $S M_{1}$ & $S M_{2}$ & $S M_{3}$ & & $S M_{1}$ & $S M_{2}$ & $\underline{S M_{3}}$ & \\
\hline$P\left(A_{1}>A_{2}\right)$ & 1 & 0.1 & 0 & $P\left(A_{2}>A_{3}\right)$ & 1 & 0 & 0 & \\
\hline$P\left(A_{1}>A_{3}\right)$ & 1 & 0 & 0 & $P\left(A_{2}>A_{4}\right)$ & 0 & 0 & 1 & \\
\hline$P\left(A_{1}>A_{4}\right)$ & 1 & 0 & 0.38 & $P\left(A_{2}>A_{5}\right)$ & 0.49 & 0 & 1 & \\
\hline$P\left(A_{1}>A_{5}\right)$ & 1 & 0 & 0.14 & $P\left(A_{2}>A_{6}\right)$ & 0 & 0 & 1 & \\
\hline$P\left(A_{1}>A_{6}\right)$ & 0.94 & 0 & 0.85 & $P\left(A_{2}>A_{7}\right)$ & 1 & 0 & 1 & \\
\hline$P\left(A_{1}>A_{7}\right)$ & 1 & 0 & 0 & $P\left(A_{2}>A_{8}\right)$ & 1 & 0 & 1 & \\
\hline$P\left(A_{1}>A_{8}\right)$ & 1 & 0 & 0.41 & $P\left(A_{4}>A_{5}\right)$ & 1 & 0.6 & 0.02 & \\
\hline$P\left(A_{3}>A_{4}\right)$ & 0 & 0 & 1 & $P\left(A_{4}>A_{6}\right)$ & 0 & 0 & 1 & \\
\hline$P\left(A_{3}>A_{5}\right)$ & 0 & 0 & 1 & $P\left(A_{4}>A_{7}\right)$ & 1 & 0 & 0 & \\
\hline$P\left(A_{3}>A_{6}\right)$ & 0 & 0 & 1 & $P\left(A_{4}>A_{8}\right)$ & 1 & 0 & 0.58 & Table VII. \\
\hline$P\left(A_{3}>A_{7}\right)$ & 0.32 & 0 & 1 & $P\left(A_{5}>A_{8}\right)$ & 1 & 0 & 1 & The possibility \\
\hline$P\left(A_{3}>A_{8}\right)$ & 0.18 & 0 & 1 & $P\left(A_{6}>A_{7}\right)$ & 1 & 0.01 & 0 & degree of interval \\
\hline$P\left(A_{5}>A_{6}\right)$ & 0 & 0 & 1 & $P\left(A_{6}>A_{8}\right)$ & 1 & 0 & 0 & numbers with \\
\hline$P\left(A_{5}>A_{7}\right)$ & 1 & 0 & 0 & $P\left(A_{7}>A_{8}\right)$ & 0.33 & 0.11 & 1 & Equation (5) \\
\hline
\end{tabular}

\begin{tabular}{|c|c|c|c|c|c|c|c|c|}
\hline & $S M_{1}$ & $S M_{2}$ & $S M_{3}$ & & $S M_{1}$ & $S M_{2}$ & $S M_{3}$ & \\
\hline$P\left(A_{1}>A_{2}\right)$ & 1 & 0.02 & 0 & $P\left(A_{2}>A_{3}\right)$ & 1 & 0 & 0 & \\
\hline$P\left(A_{1}>A_{3}\right)$ & 1 & 0 & 0 & $P\left(A_{2}>A_{4}\right)$ & 0 & 0 & 1 & \\
\hline$P\left(A_{1}>A_{4}\right)$ & 1 & 0 & 0.34 & $P\left(A_{2}>A_{5}\right)$ & 0.49 & 0 & 1 & \\
\hline$P\left(A_{1}>A_{5}\right)$ & 1 & 0 & 0.07 & $P\left(A_{2}>A_{6}\right)$ & 0 & 0 & 1 & \\
\hline$P\left(A_{1}>A_{6}\right)$ & 0.99 & 0 & 0.95 & $P\left(A_{2}>A_{7}\right)$ & 1 & 0 & 1 & \\
\hline$P\left(A_{1}>A_{7}\right)$ & 1 & 0 & 0 & $P\left(A_{2}>A_{8}\right)$ & 1 & 0 & 1 & \\
\hline$P\left(A_{1}>A_{8}\right)$ & 1 & 0 & 0.38 & $P\left(A_{4}>A_{5}\right)$ & 1 & 0.67 & 0.00 & \\
\hline$P\left(A_{3}>A_{4}\right)$ & 0 & 0 & 1 & $P\left(A_{4}>A_{6}\right)$ & 0 & 0 & 1 & \\
\hline$P\left(A_{3}>A_{5}\right)$ & 0 & 0 & 1 & $P\left(A_{4}>A_{7}\right)$ & 1 & 0 & 0 & \\
\hline$P\left(A_{3}>A_{6}\right)$ & 0 & 0 & 1 & $P\left(A_{4}>A_{8}\right)$ & 1 & 0 & 0.63 & Table VIII. \\
\hline$P\left(A_{3}>A_{7}\right)$ & 0.22 & 0 & 1 & $P\left(A_{5}>A_{8}\right)$ & 1 & 0 & 1 & The possibility \\
\hline$P\left(A_{3}>A_{8}\right)$ & 0.08 & 0 & 1 & $P\left(A_{6}>A_{7}\right)$ & 1 & 0.00 & 0 & degrees of the \\
\hline$P\left(A_{5}>A_{6}\right)$ & 0 & 0 & 1 & $P\left(A_{6}>A_{8}\right)$ & 1 & 0 & 0 & interval numbers \\
\hline$P\left(A_{5}>A_{7}\right)$ & 1 & 0 & 0 & $P\left(A_{7}>A_{8}\right)$ & 0.23 & 0.03 & 1 & with Equation (6) \\
\hline
\end{tabular}


$\mathrm{K}$

45,7

1010

degree by using an interval number. Next, we describe the arithmetic regulations and the degree of possibility $P(\tilde{A} \geqslant \tilde{B})$, and put forward simple comparison regulations by analyzing the limitations of the recent methods. Third, an extension of VIKOR method is utilized to evaluate the efficiencies of the limited public SRA problems with interval numbers.

The above numerical example shows that $A_{5}$ is the final compromise solution of the train tickets allocation. For decision alternative $A_{5}$, the per capita occupancies of $S M_{1}$, $S M_{2}$ and $S M_{3}$ are 0.53, 0.4 and 0.5, respectively, which rank 4, 4 and 4, and are also the average approximate levels. On the other hand, the comprehensive fair degrees are [0.4583, 0.5399], [0.4286, 0.4384] and [0.4583, 0.5217], respectively, which are also situated in the middle.

The illustrative example and its analysis show that relative fairness is the optimal selection in the limited public SRA problems and absolute fairness does not exist in our societies. The distributors of the limited public service resources should first investigate the probable general amounts of different channels and, second, divide the group into different types according to their preferences for different channels. Third, they should set the appropriate amounts allocated for those different groups based on the approximate average values (matching the practices). Only by doing this can we improve the comprehensive fair degrees of all consumers, and ensure all the necessary characteristics of public welfare are provided, despite limited public service resources.

\section{References}

Aghajani Mir, M., Ghazvinei, T., Sulaiman, N.M.N., Basri, N.E.A., Saheri, S., Mahmood, N.Z., Jahan, A., Begum, R.A. and Aghamohammadi, N. (2016), "Application of TOPSIS and VIKOR improved versions in a multi criteria decision analysis to develop an optimized municipal solid waste management model”, Journal of Environmental Management, Vol. 166 No. 9, pp. 109-115.

Akman, G. (2015), "Evaluating suppliers to include green supplier development programs via fuzzy c-means and VIKOR methods", Computers \& Industrial Engineering, Vol. 86 No. C, pp. 69-82.

Alikhani, R. and Azar, A. (2015), "A hybrid fuzzy satisfying optimization model for sustainable gas resources allocation”, Journal of Cleaner Production, Vol. 107 No. 16, pp. 353-365.

Azar, A. and Darvishi, Z.A. (2011), "Development and validation of a measure of justice perception in the frame of fairness theory-fuzzy approach", Expert Systems with Applications, Vol. 38 No. 6, pp. 7364-7372.

Bertsimas, D., Gupta, S. and Lulli, G. (2014), "Dynamic resource allocation: a flexible and tractable modeling framework", European Journal of Operational Research, Vol. 236 No. 1, pp. 14-26.

Chou, J.-S., Tsai, C.-F., Chen, Z.-Y. and Sun, M.-H. (2014), "Biological-based genetic algorithms for optimized disaster response resource allocation”, Computers \& Industrial Engineering, Vol. 74 No. 74, pp. 52-67.

Fan, K., You, W.J. and Li, Y.Y. (2013), “An effective modified binary particle swarm optimization algorithm for multi-objective resource allocation problem”, Applied Mathematics and Computation, Vol. 221 No. 9, pp. 257-267.

Fang, L. (2013), “A generalized DEA model for centralized resource allocation”, European Journal of Operational Research, Vol. 228 No. 2, pp. 405-412.

Fang, L. and Li, H. (2015), "Centralized resource allocation based on the cost-revenue analysis", Computers \& Industrial Engineering, Vol. 85, pp. 395-401. 
Hakim, S., Seifi, A. and Ghaemi, A. (2016), "A bi-level formulation for DEA-based centralized resource allocation under efficiency constraints”, Computers \& Industrial Engineering, Vol. 93, pp. 28-35.

Hu, Z., Chen, Y., Yao, L., Wei, C. and Li, C. (2016), “Optimal allocation of regional water resources: from a perspective of equity-efficiency tradeoff", Resources, Conservation and Recycling, Vol. 109 No. 2, pp. 102-113.

Ishibuchi, H. and Tanaka, H. (1990), "Multiobjective programming in optimization of the interval objective function”, European Journal of Operational Research, Vol. 48 No. 2, pp. 219-225.

Jiang, C., Han, X., Liu, G.R. and Liu, G.P. (2008), “A nonlinear interval number programming method for uncertain optimization problems", European Journal of Operational Research, Vol. 188 No. 1, pp. 1-13.

Kataoka, S. and Yamada, T. (2016), "Algorithms for the minimum spanning tree problem with resource allocation”, Operations Research Perspectives, Vol. 3 No. 2, pp. 5-13.

Kaushik, A. and Vidyarthi, D.P. (2016), "A green energy model for resource allocation in computational grid using dynamic threshold and GA", Sustainable Computing: Informatics and Systems, Vol. 9 No. 2, pp. 42-56.

Kuo, M.S. and Liang, G.S. (2012), "A soft computing method of performance evaluation with MCDM based on interval-valued fuzzy numbers", Applied Soft Computing, Vol. 12 No. 1, pp. 476-485.

Liu, H.-C., You, J.-X., You, X.-Y. and Shan, M.-M. (2015), "A novel approach for failure mode and effects analysis using combination weighting and fuzzy VIKOR method", Applied Soft Computing, Vol. 28 No. C, pp. 579-588.

López-Torres, L. and Prior, D. (2016), "Centralized allocation of human resources. An application to public schools", Computers \& Operations Research, Vol. 73 No. C, pp. 104-114.

Moore, R.E. (1979), Method and Application of Interval Analysis, SIAM, Philadelphia, PA.

Opricovic, S. and Tzeng, G.H. (2004), "Compromise solution by MCDM methods: a comparative analysis of VIKOR and TOPSIS”, European Journal of Operational Research, Vol. 156 No. 2 , pp. 445-455.

Opricovic, S. and Tzeng, G.H. (2007), "Extended VIKOR method in comparison with outranking methods", European Journal of Operational Research, Vol. 178 No. 2, pp. 514-529.

Pandremmenou, K., Kondi, L.P. and Parsopoulos, K.E. (2015), “A study on visual sensor network cross layer resource allocation using quality-based criteria and metaheuristic optimization algorithms", Applied Soft Computing, Vol. 26 No. 26, pp. 149-165.

Park, J., Ellis, G.D., Kim, S.S. and Prideaux, B. (2010), "An investigation of perceptions of social equity and price acceptability judgments for campers in the US national forest”, Tourism Management, Vol. 31 No. 2, pp. 202-212.

Pla, A., López, B. and Murillo, J. (2015), "Multi-dimensional fairness for auction-based resource allocation”, Knowledge-Based Systems, Vol. 73 No. 3, pp. 134-148.

Rostamzadeh, R., Govindan, K., Esmaeili, A. and Sabaghi, M. (2015), "Application of fuzzy VIKOR for evaluation of green supply chain management practices", Ecological Indicators, Vol. 49 No. 2, pp. 188-203.

Sayadi, M.K., Heydari, M. and Shahanaghi, K. (2009), "Extension of VIKOR method for decision making problem with interval numbers", Applied Mathematical Modelling, Vol. 33 No. 5, pp. 2257-2262.

Sengupta, A. and Pal, T.K. (2000), "On comparing interval numbers", European Journal of Operational Research, Vol. 127 No. 1, pp. 28-43.

Shabtay, D., Steiner, G. and Zhang, R. (2016), "Optimal coordination of resource allocation, due date assignment and scheduling decisions”, Omega, Vol. 32 No. 2, pp. 56-68. 
$\mathrm{K}$

45,7

1012

Sharma, N. and Anpalagan, A. (2015), "Differential evolution aided adaptive resource allocation in OFDMA systems with proportional rate constraints", Applied Soft Computing, Vol. 34 No. C, pp. 39-50.

Sung, I. and Lee, T. (2016), "Optimal allocation of emergency medical resources in a mass casualty incident: patient prioritization by column generation", European Journal of Operational Research, Vol. 252 No. 2, pp. 623-634.

Vahabzadeh, A.H., Asiaei, A. and Zailani, S. (2015), "Green decision-making model in reverse logistics using FUZZY-VIKOR method”, Resources, Conservation and Recycling, Vol. 103 No. 10, pp. 125-138.

Wu, J., An, Q.X. and Liang, L. (2013), "DEA based resource allocation considering environmental factors", Mathematical and Computer Modelling, Vol. 58 Nos 5/6, pp. 1128-1137.

Xiong, J., Leus, R., Yang, Z. and Abbass, H.A. (2016), "Evolutionary multi-objective resource allocation and scheduling in the Chinese navigation satellite system project", European Journal of Operational Research, Vol. 251 No. 2, pp. 662-675.

Xu, L., Qian, F., Li, Y., Li, Q., Yang, Y.-W. and Xu, J. (2016), "Resource allocation based on quantum particle swarm optimization and RBF neural network for overlay cognitive OFDM System”, Neurocomputing, Vol. 173 No. 1, pp. 1250-1256.

$\mathrm{Xu}$, Z.S. (2008), "Dependent uncertain ordered weighted aggregation operators", Information Fusion, Vol. 9 No. 2, pp. 310-316.

Yang, Z. and Zhang, Q. (2015), "Resource allocation based on DEA and modified Shapley value", Applied Mathematics and Computation, Vol. 263 No. 1, pp. 280-286.

Yazdani, M. and Payam, A.F. (2015), "A comparative study on material selection of micro electromechanical systems electrostatic actuators using Ashby, VIKOR and TOPSIS", Materials and Design, Vol. 65 No. 1, pp. 328-334.

You, X.-Y., You, J.-X., Liu, H.-C. and Zhen, L. (2015), “Group multi-criteria supplier selection using an extended VIKOR method with interval 2-tuple linguistic information", Expert Systems with Applications, Vol. 42 No. 4, pp. 1906-1916.

Yu, V.F. and Hu, K.J. (2014), “An integrated approach for resource allocation in manufacturing plants”, Applied Mathematics and Computation, Vol. 245 No. 245, pp. 416-426.

Zhang, C., Liu, X., Jiang, Y.P., Fan, B. and Song, X. (2016), “A two-stage resource allocation model for life line systems quick response with vulnerability analysis", European Journal of Operational Research, Vol. 250 No. 3, pp. 855-864.

\section{Further reading}

Nicklin, J.M., Greenbaum, R., McNall, L.A., Folger, R. and Williams, K.J. (2011), “The importance of contextual variables when judging fairness: an examination of counterfactual thoughts and fairness theory", Organizational Behavior and Human Decision Processes, Vol. 114 No. 2, pp. 127-141.

\section{Corresponding author}

Wenqi Jiang can be contacted at: wqjiang@ustc.edu

For instructions on how to order reprints of this article, please visit our website:

www.emeraldgrouppublishing.com/licensing/reprints.htm

Or contact us for further details: permissions@emeraldinsight.com 